\title{
Effects of etching and adhesive applications on the bond strength between composite resin and glass-ionomer cements
}

\author{
Tijen PAMIR', Bilge Hakan ŞEN² ${ }^{2}$ Özgür EVCIN ${ }^{3}$ \\ 1- DDS, PhD, Professor, Department of Restorative Dentistry, School of Dentistry, Ege University, Bornova, Izmir, Turkey. \\ 2- DDS, PhD, Professor, Department of Endodontology, School of Dentistry, Ege University, Bornova, Izmir, Turkey. \\ 3- DDS, PhD, Private Dentist, (Former Research Assistant in Department of Restorative Dentistry), School of Dentistry, Ege University, Bornova, Izmir, Turkey. \\ Corresponding address: Tijen Pamir - Ege University School of Dentistry, Department of Restorative Dentistry, 35100 - Bornova - Izmir - Turkey - Phone: \\ +90-232-388-03-28 - Fax: +90-232-388-03-25 - E-mail: tijenpamir@gmail.com
}

Received: March 13, 2012 - Modification:August 16, 2012 - Accepted: September 14, 2012

\section{ABSTRACT}

O bjective: This study determined the effects of various surface treatment modalities on the bond strength of composite resins to glass-ionomer cements. Material and Methods: Conventional (Ketac ${ }^{\text {TM }}$ Molar Quick Applicap ${ }^{\text {TM }}$ ) or resin-modified (Photac ${ }^{\text {TM }}$ Fil Quick Aplicap ${ }^{\mathrm{TM}}$ ) glass-ionomer cements were prepared. Two-step etch-rinse \& bond adhesive (Adper ${ }^{\mathrm{TM}}$ Single Bond 2) or single-step self-etching adhesive (Adper ${ }^{\mathrm{TM}}$ Prompt $^{\mathrm{TM}}$ L-Pop ${ }^{\mathrm{TM}}$ ) was applied to the set cements. In the etch-rinse \& bond group, the sample surfaces were pre-treated as follows: (1) no etching, (2) 15 s of etching with $35 \%$ phosphoric acid, (3) $30 \mathrm{~s}$ of etching, and (4) $60 \mathrm{~s}$ of etching. Following the placement of the composite resin (Filtek ${ }^{\mathrm{TM}} \mathrm{Z250}$ ), the bond strength was measured in a universal testing machine and the data obtained were analyzed with the two-way analysis of variance (ANOVA) followed by the Tukey's HSD post hoc analysis $(p=0.05)$. Then, the fractured surfaces were examined by scanning electron microscopy. Results: The bond strength of the composite resin to the conventional glass-ionomer cement was significantly lower than that to the resin-modified glass-ionomer cement $(p<0.001)$. No significant differences were determined between the self-etching and etch-rinse $\&$ bond adhesives at any etching time $(p>0.05)$. However, a greater bond strength was obtained with $30 \mathrm{~s}$ of phosphoric acid application. Conclusions: The resin-modified glass-ionomer cement improved the bond strength of the composite resin to the glass-ionomer cement. Both etch-rinse $\&$ bond and self-etching adhesives may be used effectively in the lamination of glass-ionomer cements. However, an etching time of at least $30 \mathrm{~s}$ appears to be optimal.

Key words: Glass-ionomer cements. Composite resins. Acid etching. Dental adhesives.

\section{INTRODUCTION}

The extensive range of tooth-colored materials for esthetic restorations on the market are mainly branches of two separate groups - glass-ionomer cements and composite resins - each with its own sub-groups ${ }^{16}$. Following their introduction in the late 1960s, composite resins have gained general respect, due to their esthetically pleasing appearance and stability within the oral environment. However, they have several disadvantages, such as polymerization shrinkage, potential failure of adhesion leading to secondary caries, and a relatively high co-efficient of thermal expansion in vitro ${ }^{12}$. In contrast, some researchers have suggested that glass-ionomer cements offer stronger inhibition of secondary caries compared with composite resin ${ }^{7,28}$, since they act as a reservoir for fluoride release ${ }^{17}$. The reaction of glass-ionomer cements display a similar behaviour to dentin under thermal stimuli2. This feature plays an important role during the mechanical and thermal loading of the material. In contrast, resin materials show a deformation different from that of the dentin under mechanical and thermal stress ${ }^{20}$. Therefore, due to its stressabsorbing interfacial layer characteristics, glass- 
ionomer cement has been recommended as a restorative material for the lamination (sandwich) technique ${ }^{16,29}$

The lamination technique can be applied for all deep and undermined cavities where composite resin is the primary choice. In particular cases where one or more margins of restoration exist on the dentin, lamination over a glass-ionomer cement is strongly recommended to enhance adhesion to the dentin and limit microleakage. In this technique, the glass-ionomer cement represents the lost dentin, although composite resin is used instead of enamel. Two types of glass-ionomer cements, i.e., conventional or resin-modified, can be used for this purpose, even though they have differences in the adhesion mechanism, setting reaction, and sensitivity to the moisture of the materials. The expectations from the lamination technique are to combine the advantages of both glass-ionomer cements and composite resins to enhance the clinical serviceability of the restoration ${ }^{16,20}$. When the current diversity of adhesive systems and differences in adhesion and setting mechanisms of the restorative materials are taken into consideration, the bonding of the laminated materials to each other becomes important, as well as the bonding of any material to the tooth structures. Until now however, researchers have not reached a consensus on the type and duration of surface treatment modalities over glassionomer cements. Therefore, in this study, our null hypotheses were that adhesive type and duration of the acid-etching procedure would not affect the bond strength of the composite resin to glass-ionomer cements. Furthermore, the type of glass-ionomer cement would not critically influence the bonding quality.

\section{MATERIAL AND METHODS}

Study design and surface treatment modalities over the glass-ionomer cement (GIC) samples were performed as presented in Figure 1. One hundred and fifty specimens - 75 each of conventional (C-GIC) (Ketac $^{\text {TM }}$ Molar Quick Applicap ${ }^{\text {TM }}$, 3M ESPE AG Dental Product, Seefeld, Germany) and resin-modified glass-ionomer cement (RM-GIC) (Photac ${ }^{\mathrm{TM}}$ Fil Quick Applicap $^{\mathrm{TM}}$, 3M ESPE AG Dental Product, Seefeld, Germany) - were prepared in Delrin (acetal resin) moulds containing cylinders $4 \mathrm{~mm}$ in diameter and 6 $\mathrm{mm}$ long. During the setting, the bottoms and tops of the moulds were covered with cellulose acetate strips and glass microscope slides under hand pressure, to produce a smooth surface. For the C-GIC, the assembly was held in place for $10 \mathrm{~min}$, whereas the RM-GIC was light-cured for $20 \mathrm{~s}$ on each side of the material in a LED (light-emitting diode) dental curing apparatus (Bluephase, Ivoclar/Vivadent, Schaan, Liechtenstein) having $1100 \mathrm{~mW} / \mathrm{cm}^{2}$ light intensity.
After polymerization, the cylinders were removed from the moulds, and the bonding surfaces were ground flat with 600-grit $\mathrm{Al}_{2} \mathrm{O}_{3}$ papers (Buehler, Lake Bluff, IL, USA). Both the C-GIC and RM-GIC samples were divided into 5 groups, each consisting of 15 samples.

Following the surface treatment procedure, the samples were placed into second split Delrin moulds with holes $4 \mathrm{~mm}$ in diameter and $12 \mathrm{~mm}$ in depth, and composite resin material Filtek Z250 (3M ESPE AG Dental Products, Seefeld, Germany) was incrementally added on top of the GIC samples. A LED curing unit was used to polymerize the composite resin layers for $20 \mathrm{~s}$ at a LOF (low-power curing mode with $650 \mathrm{~mW} / \mathrm{cm}^{2}$ light intensity) plus 15 $\mathrm{s}$ at a HIF mode (high-power with $1100 \mathrm{~mW} / \mathrm{cm}^{2}$ light intensity). All experimental procedures were carried out at room temperature, and cylindrical specimens of each material were fabricated according to the manufacturer's instructions. After curing, the second split mould was removed, and samples were kept in a $100 \%$ humidity incubator at $37^{\circ} \mathrm{C}$ for $48 \mathrm{~h}$.

The shear bond strength of each specimen was measured in a universal testing machine (Shimadzu Autograph, AGS-J 5 kN, Shimadzu Corporation, Tokyo, Japan) at a cross-head speed of $0.5 \mathrm{~mm} /$ min. The knife edge blade was applied vertically against the specimens to load $0.5 \mathrm{~mm}$ away from the bonding area of the materials. The specimens were loaded until failure and the failure load was converted to failure stress the TRAPEZIUM2 software program (Shimadzu Corporation, Tokyo, Japan) on the computer connected to a universal testing machine. Mean and standard deviations were calculated, and the two-way analysis of variance (ANOVA) was used to determine the significance of differences among the GICs and the surface treatment modalities. Pairwise comparisons were performed with the Tukey's HSD post hoc analysis $(p=0.05)$.

Visual examination of the failure modes of the bonding specimens was accomplished by viewing all of the de-bonded specimens under a light microscope at $x 10$ or $x 20$ magnification. Accordingly, the samples were sorted into 3 groups: Fractures were called "adhesive failure" when the composite resin was removed from the glass-ionomer surfaces without residual debris, "cohesive failure" when fracture occurred inside the restoratives, and "mixed failure" when both occurred. Scanning electron microscopy (SEM) (JEOL-5200, Tokyo, Japan) was used to observe the fractured surfaces of three samples from each group.

\section{RESULTS}

As a result of the statistical analysis, it was determined that the interaction between the GICs and adhesives was not significant $(p=0.318)$. That 


\begin{tabular}{|c|c|c|c|c|c|}
\hline \multirow{5}{*}{$\begin{array}{l}\text { Glass- } \\
\text { ionomer } \\
\text { cements }\end{array}$} & \multicolumn{4}{|c|}{ Surface treatment modalities } & Self-etch \\
\hline & \multicolumn{4}{|c|}{ Etch, rinse \& bond } & \multirow{4}{*}{$\begin{array}{c}\text { All in one } \\
\text { Adper }^{\mathrm{TM}} \\
\text { Prompt }^{\mathrm{TM}} \text { L-Pop }{ }^{\mathrm{TM}} \\
\text { (3M ESPE Dental } \\
\text { Products, } \\
\text { Seefeld- } \\
\text { Germany) }\end{array}$} \\
\hline & \multicolumn{4}{|c|}{$M E$} & \\
\hline & \multicolumn{4}{|c|}{$\% 35$ phosphoric acid } & \\
\hline & No etch & $15 s$ & $30 \mathrm{~s}$ & $60 \mathrm{~s}$ & \\
\hline $\begin{array}{c}\text { Ketac Molar } \\
\text { Quick Aplicap } \\
\text { The capsules } \\
\text { were } \\
\text { activated and } \\
\text { mixed using } \\
\text { VariMix at } \\
\text { medium frequency } \\
\text { for } 7 \text { s. Then GICs } \\
\text { were placed into } \\
\text { the mould and } \\
\text { waited } 10 \text { min } \\
\text { before any surface } \\
\text { treatment } \\
\text { application. }\end{array}$ & \begin{tabular}{|} 
Adper Single \\
Bond 2 was \\
directly brushed \\
onto the moist \\
samples at $2-3$ \\
consecutive coats \\
for 15 s, and \\
dried \\
gently for 5 s. \\
Then light cured \\
with LED at LOF \\
mode for \\
10 s.
\end{tabular} & $\begin{array}{l}\text { 35\% phosphoric } \\
\text { acid was applied } \\
\text { onto the GIC } \\
\text { samples for } 15 \mathrm{~s} \text {, } \\
\text { washed and } \\
\text { rinsed, blew } \\
\text { excess water off } \\
\text { leaving the GIC } \\
\text { samples moist. } \\
\text { Adper Single } \\
\text { Bond } 2 \\
\text { application was } \\
\text { same as } \\
\text { described } \\
\text { previously. }\end{array}$ & $\begin{array}{l}\text { Acid etching with } \\
35 \% \text { phosphoric } \\
\text { acid for } 30 \mathrm{sec} \text {, } \\
\text { and then } \\
\text { Adper Single } \\
\text { Bond } 2 \\
\text { application in } \\
\text { same manner. }\end{array}$ & $\begin{array}{l}\text { Acid etching with } \\
35 \% \text { phosphoric } \\
\text { acid for } 60 \mathrm{sec} \text {, } \\
\text { and then } \\
\text { Adper Single } \\
\text { Bond } \\
2 \\
\text { application } \\
\text { in } \\
\text { same manner. }\end{array}$ & $\begin{array}{l}\text { Adper Prompt L- } \\
\text { Pop was } \\
\text { activated. } \\
\text { Adhesive was } \\
\text { brushed onto the } \\
\text { surface of the } \\
\text { GIC samples, } \\
\text { massaged it in for } \\
15 \text { s applying } \\
\text { pressure. Gentle } \\
\text { stream of air was } \\
\text { used thoroughly } \\
\text { dry the adhesive } \\
\text { to a thin film. } \\
\text { Then second } \\
\text { application was } \\
\text { performed } \\
\text { without massage } \\
\text { and dried gently. } \\
\text { The adhesive was } \\
\text { light-cured with } \\
\text { LED at LOF } \\
\text { mode for } 10 \text { s. }\end{array}$ \\
\hline $\begin{array}{c}\text { Photac Fil } \\
\text { Quick Aplicap } \\
\text { The capsules } \\
\text { activated and } \\
\text { mixed using } \\
\text { VariMix at high } \\
\text { frequency for } 9 \mathrm{~s} \text {. } \\
\text { Then GICs were } \\
\text { placed into the } \\
\text { mould } \\
\text { incrementally. } \\
\text { Each layer was } \\
\text { cured for } 20 \mathrm{~s} \text { at } \\
\text { SOF mode of } \\
\text { LED. }\end{array}$ & $\begin{array}{c}\text { Acid etching } \\
\text { procedures and } \\
\text { Adper Single } \\
\text { Bond application } \\
\text { were same as } \\
\text { that } \\
\text { of the Ketac } \\
\text { Molar Quick } \\
\text { Aplicap group. }\end{array}$ & $\begin{array}{l}\text { Procedure was } \\
\text { same as that of } \\
\text { the Ketac Molar } \\
\text { Quick Aplicap } \\
\text { group. }\end{array}$ & $\begin{array}{c}\text { Procedure was } \\
\text { same as that of } \\
\text { the Ketac Molar } \\
\text { Quick Aplicap } \\
\text { group. }\end{array}$ & $\begin{array}{c}\text { Procedure was } \\
\text { same as that of } \\
\text { the Ketac Molar } \\
\text { Quick Aplicap } \\
\text { group. }\end{array}$ & $\begin{array}{l}\text { Adper Prompt L- } \\
\text { Pop application } \\
\text { procedure was } \\
\text { same as that of } \\
\text { the Ketac Molar } \\
\text { Quick Aplicap } \\
\text { group. }\end{array}$ \\
\hline
\end{tabular}

$\mathrm{GIC}=$ glass-ionomer cement; LED=light-emitting diode; LOF=low-power curing mode with $650 \mathrm{~mW} / \mathrm{cm}^{2}$ light intensity

Figure 1- Experimental design and surface treatment modalities of GIC samples 
Table 1- Mean bond strength (MPa) of resin composite to two different types of glass-ionomer cements treated with various surface treatment procedures of different adhesive systems. Same symbol and letters within a group indicate statistically significant differences

\begin{tabular}{|c|c|c|c|c|c|}
\hline & \multicolumn{4}{|c|}{ Surface treatment modalities } & $\begin{array}{l}\text { Self-etch } \\
\text { (No rinse) }\end{array}$ \\
\hline \multicolumn{6}{|c|}{ Etch, rinse \& bond } \\
\hline \multicolumn{6}{|c|}{$35 \%$ phosphoric acid } \\
\hline $\begin{array}{l}\text { Glass-ionomer } \\
\text { cements }\end{array}$ & $\begin{array}{c}\text { No etch } \\
\mathrm{MPa} \pm(\mathrm{SD})\end{array}$ & $\begin{array}{c}15 \mathrm{~s} \\
\mathrm{MPa} \pm(\mathrm{SD})\end{array}$ & $\begin{array}{c}30 \mathrm{~s} \\
\mathrm{MPa} \pm(\mathrm{SD})\end{array}$ & $\begin{array}{c}60 \mathrm{~s} \\
\mathrm{MPa} \pm(\mathrm{SD})\end{array}$ & $\begin{array}{c}\text { All in one } \\
M P a \pm(S D)\end{array}$ \\
\hline $\begin{array}{l}\text { Ketac Molar Quick } \\
\text { Applicap* }\end{array}$ & $6.1 \pm(2.3)^{a}$ & $5.1 \pm(1.6)^{b, c}$ & $7.1 \pm(1.7)^{\mathrm{a}, \mathrm{b}}$ & $8.0 \pm(2.1)^{c}$ & $6.0 \pm(2.2)$ \\
\hline $\begin{array}{c}\text { Photac Fil Quick } \\
\text { Applicap* }\end{array}$ & $10.1 \pm(2.7)^{d}$ & $10.0 \pm(2.3)^{e, f}$ & $12.7 \pm(2.9)^{\mathrm{d}, \mathrm{e}}$ & $12.0 \pm(2.8)^{f}$ & $12.8 \pm(2.5)$ \\
\hline
\end{tabular}

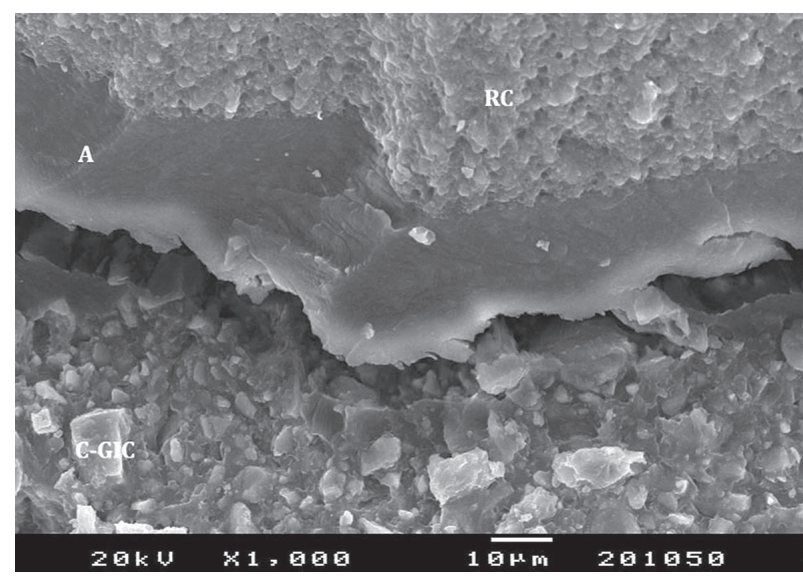

Figure 2- Scanning electron microscopy (SEM) evaluation indicated cracks in certain areas of bonding between adhesive and conventional glass-ionomer cement $(\mathrm{C}-\mathrm{GIC})$. RC= composite resin

is, for both types of glass-ionomer cements used in this study, the effects of any surface treatment were similar. The mean shear bond strengths, standard deviations, and statistical differences for each group are presented in Table 1 . There were no significant differences in the bond strengths between the "selfetch" and "etch \& rinse" adhesives at any time period ( $p>0.05)$. When 35\% phosphoric acid pretreatments of the "etch \& rinse" adhesive system were compared for various application times, the highest bond strength values were obtained at $60 \mathrm{~s}$ for the Ketac Molar and $30 \mathrm{~s}$ for the Photac Fil. However, there were no statistically significant differences between 30 and $60 \mathrm{~s}$ of the etching application time with $35 \%$ phosphoric acid for both types of GICs $(p>0.05)$. Furthermore, the bond strength of the composite resin $(R C)$ to the $C$-GIC was significantly lower than that to the RM-GIC $(p<0.001)$. SEM evaluation of the fractured surfaces indicated the presence of cracks in some interfaces between the C-GIC \& adhesive $\&$ the RC (Figure 2). In contrast, good interlocking adhesion was exhibited between the RM-GIC and the adhesive (Figure 3).

Figures 4 and 5 show the results of the failure mode for the shear strengths of the specimens bonded to the C-GIC and RM-GIC, respectively. Adhesive failure was observed only when the composite resin was bonded to the C-GIC Ketac Molar. Most of the C-GIC samples exhibited mixedtype failure modes (Figure 4), whereas cohesive failure was the dominant mode in the RM-GIC groups (Figure 5). Figure 6 shows the adhesive coating and small deposits of RC on a fractured area of a sample where the self-etch adhesive system Prompt L-Pop was used. Mixed-type sample failure is exhibited in Figure 7, where 35\% phosphoric acid was applied for $60 \mathrm{~s}$.

\section{DISCUSSION}

Lamination of the composite resin over the glass-ionomer material has been recommended as a viable restoration alternative, especially in areas of higher microleakage risk, such as with the coronal restoration of an endodontically treated tooth. Coronal leakage is one of the most important factors in determining the long-term success of endodontic treatment ${ }^{10,19}$. It has been noted that the placement of an intraorifice barrier following the root canal filling is beneficial in delaying and preventing coronal microleakage ${ }^{22}$. A laboratory study ${ }^{1}$ demonstrated that a conventional glass-ionomer cement, with its superior sealing ability, would be the best intraorifice barrier material. Furthermore, during root canal therapy, a large amount of dentin is generally lost due to the nature of this treatment. Since glass-ionomer cement is often known as a biomimetic material, with mechanical properties similar to those of the dentin ${ }^{29}$, it can replace the lost dentin. Due to these favorable properties mentioned above, glass-ionomer cements were often applied in combination with composite resins in the coronal restoration of endodontically treated teeth.

Another high-risk area for microleakage in 


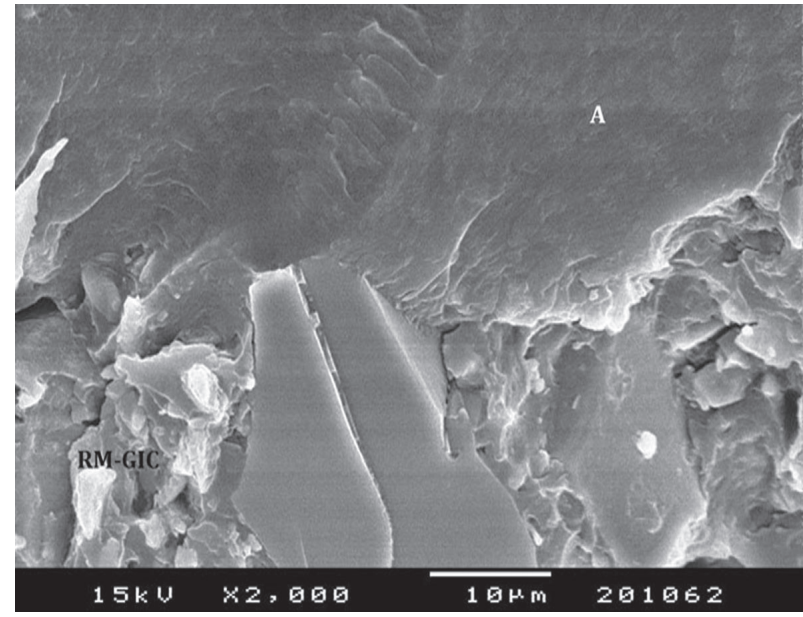

Figure 3- Good interlocking adhesion between resinmodified glass-ionomer cement (RM-GIC) and adhesive

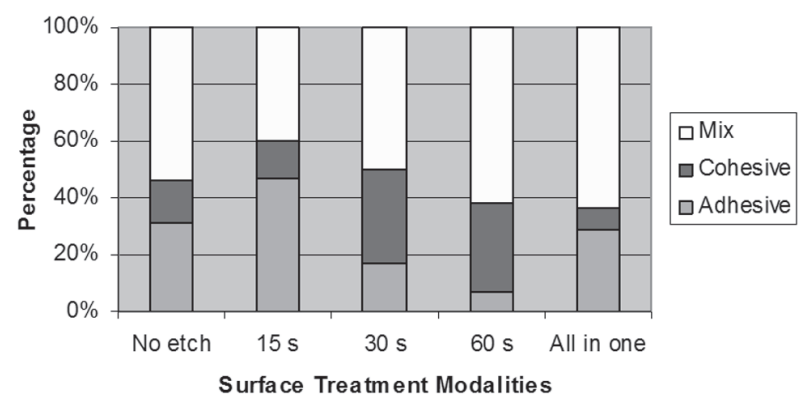

Figure 4- Fracture modes of the specimens bonded to Ketac Molar Quick Applicap according to various surface treatment modalities

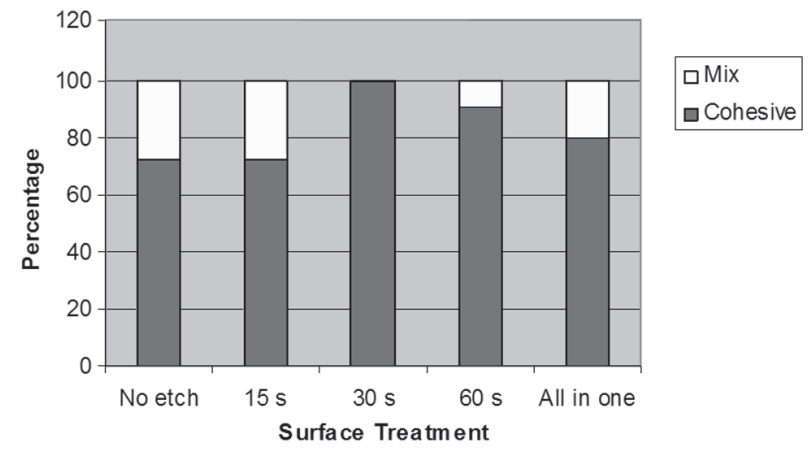

Figure 5- Fracture modes of the specimens bonded to Photac Fil Quick Applicap according to various surface treatment modalities

operative dentistry is the gingival region of a tooth. The heterogeneous nature of the dentin and the difficulties of moisture control in this area cause complications for perfect sealing by the dentinal bond $^{27}$. In all large and deep cavities with one or more restoration margins located within the dentin, the lamination technique is recommended to enhance adhesion and to limit microleakage, if composite resin is preferred as the primary filling material ${ }^{16,24}$. In this situation, the practitioner can

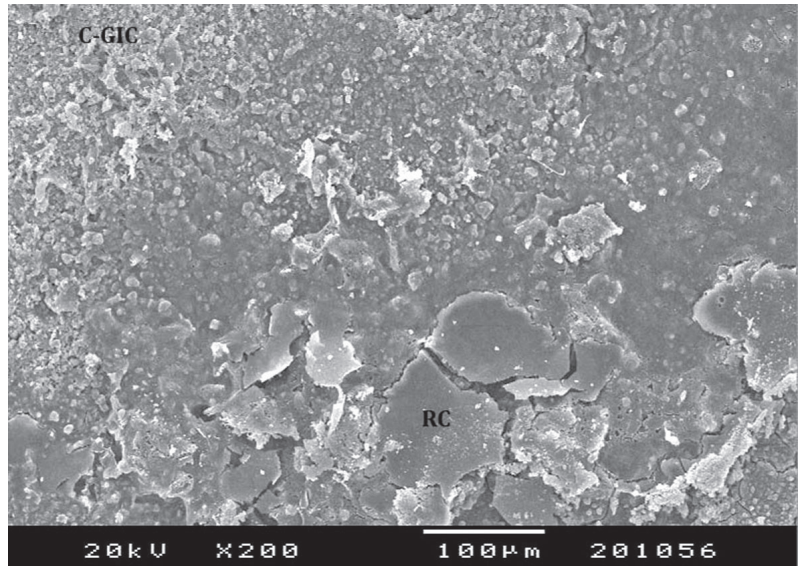

Figure 6- Prompt L-Pop adhesive coating and small deposits of composite resin (RC) on the conventional glass-ionomer cement (C-GIC) surface

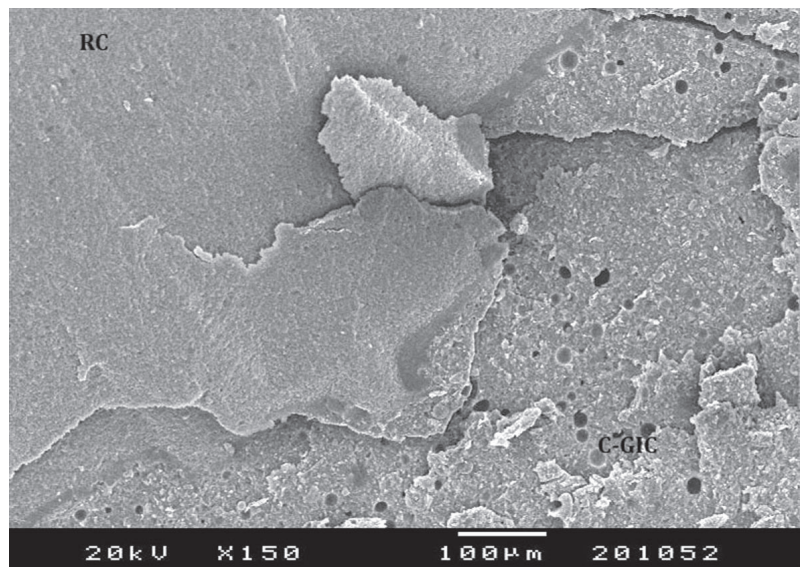

Figure 7- Mixed type fracture in the debonded area of a sample in which Adper Single Bond was used. C-GIG= conventional glass ionomer cement

leave the glass-ionomer cement exposed to the oral environment in the gingival area. Even if microleakage persists in this area, the possibility of fluoride recharge and release from the glassionomer cement offers the potential of preventing secondary caries. Furthermore, with this technique, practitioners can take advantage of the major benefits of glass-ionomer cement - i.e., its stress absorbing nature, cation releasing property, different setting reaction compensating shrinkage, good ionic adhesion and low modulus of elasticity ${ }^{5}$.

The bond strength between glass-ionomer cement and composite resin is certainly important for both the retention of the resin restoration and prevention of microleakage. Although the need for enamel and dentin pretreatment has been well-established in the literature, the need for surface treatment over the GIC before composite resin lamination in sandwich restorations remains controversial. In past research, there was no consensus on the necessity of acid-etching over the glass-ionomer surface to improve the bond 
strength of composite resin ${ }^{11,23,25}$. McLean, et al. ${ }^{15}$ (1985) advocated the etching procedure for $60 \mathrm{~s}$ to obtain closer contact and mechanical interlocking between the bonding agent and the porosity created by acid-etching of the cement surface. However, some investigators have rejected the acid-etching procedure, since it leads to a decrease in the cohesive strength of the cement ${ }^{21,25}$. Sheth, et al. ${ }^{21}$ (1989) suggested that acid-etching of the glass-ionomer cement would only undermine the cement surface, and hence cohesive failure of this weakened zone would be determined instead of a "true" interfacial resin bond strength. However, microleakage results of their study did not reveal any differences between the etched and nonetched samples. Further, in the SEM evaluation of the current study, we did not observe subsurface deterioration in the glass-ionomer cement surfaces where acid-etching was applied.

Researchers, who even suggested the etching procedure, have not reached a consensus on standardizing the etching time yet. Some authors have restricted the etching process to $15 \mathrm{~s}$, because the surface deterioration of the cements occurs with a prolonged time ${ }^{4}$. There are studies recommending 30 and/or $60 \mathrm{~s}$ of etching time for a desirable bonding effect $8,13,25$. All of these previous studies were carried out with a $37 \%$ phosphoric acid application. From past to present, however, restorative materials, bonding systems, and their application procedures have been greatly improved. Therefore, the restorative materials and the surface treatment modalities of the glass-ionomer cement are still critically important. Our findings demonstrated that the etching process improved the bond strength of the composite resin. However, when the "etch \& rinse" system was used, $30 \mathrm{~s}$ seemed to be the optimal etching time of $35 \%$ phosphoric acid for both the C-GIC and RM-GIC. The findings of this study are not in agreement with those of other studies $3,9,26,30$ which have suggested that the etching process did not improve the bond strength of the RC to the GIC. In the aforementioned study, however, etching had been applied for $15 \mathrm{~s}$. Our opinion is that this application period may not be adequate to determine significant differences between the etched and non-etched GIC samples. Indeed, we did not observe any statistical differences between the "no etch" and 15 s groups (Table 1 ). On the contrary, the effect of etching time became significant at $30 \mathrm{~s}$, when the procedure was carried out with $35 \%$ phosphoric acid. The effect of the "self-etch adhesive" to the GICs was not different from that of the "etch \& rinse" system since the bond strengths obtained with both adhesive systems were not significantly different. In this study, failure modes within each GIC group seemed to be similar, with the exception of the specimens of the PhotacFil group, which were etched with 35\% phosphoric acid for $30 \mathrm{~s}$ (Figures 4 and 5). Only cohesive failure was seen in this application group (Figure 5 ). This result might confirm the strong bonding between the RC and RM-GIC, especially when 35\% phosphoric acid etching was applied for 30 seconds.

Indeed, lamination over the RM-GIC seems to be more effective, since the bond strength of the RC to the RM-GIC was significantly higher compared with that of the C-GIC. This is in agreement with the results of previous reports ${ }^{26,30}$. It has been suggested that a similarity in compositions of both materials and curing mechanisms by the free-radical initiator system might be responsible for the increased bond strengths $s^{4,6,14}$. SEM photographs of the current study indicated good interlocking adhesion between the RM-GIC and RC. Furthermore, fracture types of the specimens bonded to the PhotacFil Quick Applicap were dominantly cohesive within the GIC.

Although in vitro studies highlighted the promising results of the lamination technique, Opdam, et al. ${ }^{18}$ (2007) reported an increased failure rate for closed-sandwich restorations after 9 years. However, their study was based on the database of Classes I and II composite resin restorations placed with and without the RM-GIC lining. According to their treatment protocol, even though the cavity walls were etched with $38 \%$ phosphoric acid before the GIC liners were placed, a bonding agent was applied to the surface of the GIC without the etching procedure. Besides, it is known that a strong acid application to the tooth structures was not proposed prior to the GIC placement. Those factors might be the reason for the failure in their sandwich restorations. With the findings of our laboratory study, it seems that acid-etching of a glass-ionomer base will improve the bonding capability of a composite resin to the RM-GIC.

Some researchers claimed that the technique of a glass-ionomer sample preparation affected the bond strength results ${ }^{9,21}$. Their suggestion was that the smooth, almost glazed surfaces of non-etched GIC, which were produced when the cement was allowed to set against a glass and/or mylar strip, would lead to an inferior bond compared with that of etched surfaces. In this study, the surfaces of the GIC samples were roughened with 600-grit $\mathrm{Al}_{2} \mathrm{O}_{3}$ discs before the surface treatment modalities were applied, since glazed cement surfaces cannot be reproduced in clinical conditions.

\section{CONCLUSIONS}

Within the limitations of this study, the following conclusions may be drawn:

The use of RM-GIC improves the bond strength of the RC to the GIC. 
Either two-step "etch, rinse \& bond" or singlestep "self-etch" adhesive systems may be preferred in the bonding of the RC to the GICs.

For an etching procedure via $35 \%$ phosphoric acid, the optimal etching time seems to be $30 \mathrm{~s}$.

\section{ACKNOWLEDGMENTS}

This study was supported mainly by Ege University Research Funds (project number 2005Diş-09). The content is solely the responsibility of the authors and does not necessarily represent the official views of Ege University.

\section{REFERENCES}

1- Çelik EU, Yapar AGD, Ateş M, Şen BH. Bacterial microleakage of barrier materials in obturated root canals. J Endod. 2006;32:10746.

2- Davidson CL. Advances in glass-ionomer cements. J Appl Oral Sci. 2006;14:3-9.

3- Della Bona A, Pinzetta C, Rosa V. Effect of acid etching of glass ionomer cement surface on the microleakage of sandwich restorations. J Appl Oral Sci. 2007;15:230-4.

4- Farah CS, Orton VG, Collard SM. Shear bond strength of chemical and light-cured glass ionomer cements bonded to composite resins. Aust Dent J. 1998;43:81-6.

5- Ferrari M. Use of glass ionomers as bondings, linings, or bases. In: Davidson CL, Mjör IA, eds. Advances in glass-ionomer cements. Berlin: Quintessence Publishing; 1999. p.137-48.

6- Fortin D, Vargas MA, Swift EJ Jr. Bonding of composite resins to resin-modified glass ionomers. Am J Dent. 1995;8:201-4.

7- Gama-Teixeira A, Simionato MR, Elian SN, Sobral MA, Cerqueira Luz MA. Streptococcus mutans-induced secondary caries adjacent to glass ionomer cement, composite resin and amalgam restorations in vitro. Braz Oral Res. 2007;21:368-74.

8- Garcia-Godoy F, Draheim RN, Titus HW. Shear bond strength of a posterior composite resin to glass ionomer bases. Quintessence Int. $1988 ; 19: 357-9$.

9- Gopikrishna V, Abarajithan M, Krithikadatta J, Kandaswamy D. Shear bond strength evaluation of composite resin bonded to GIC using three different adhesives. Oper Dent. 2009;34:467-71. 10- Heling I, Gorfil C, Slutzky H, Kopolovic K, Zalkind M, SlutzkyGoldberg I. Endodontic failure caused by inadequate restorative procedures: review and treatment recommendations. J Prosthet Dent. 2002;87:674-8.

11- Hinoura K, Moore BK, Philips RW. Tensile bond strength between glass ionomer cement and composite resins. J Am Dent Assoc. 1987;114:167-72.
12- Jandt KD, Sigusch BU. Future perspectives of resin based materials. Dent Mater. 2009;25:1001-6.

13- Joynt RB, Williams D, Davis EL, Wieczkowski G Jr. Effects of etching time on surface morphology and adhesion of a posterior resin to glass-ionomer cement. J Prosthet Dent. 1989;61:310-4. 14- Li J, Liu Y, Liu Y, Söremark R, Sundström F. Flexural strength of resin-modified glass ionomer cements and their bond strength to dental composites. Acta Odontol Scand. 1996;54:55-8.

15- McLean JW, Powis DR, Prosser HJ, Wilson AD. The use of glass-ionomer cements in bonding composite resin to dentine. Br Dent J. 1985;158:410-4.

16- Mount GJ, Tyas MJ, Ferracane JL, Nicholson JW, Berg JH, Simonsen RJ. A revised classification for direct tooth-colored restorative materials. Quintessence Int. 2009;40:691-7.

17- Okuyama K, Murata Y, Pereira PN, Miguez PA, Komatsu H, Sano $\mathrm{H}$. Fluoride release and uptake by various dental materials after fluoride application. Am J Dent. 2006;19:123-7.

18- Opdam NJ, Bronkhorst EM, Roeters JM, Loomans BA. Longevity and reasons for failure of sandwich and total-etch posterior composite resin restorations. J Adhes Dent. 2007;9:469-75.

19- Ray HA, Trope M. Periapical status of endodontically treated teeth in relation to the technical quality of the root filling and the coronal restoration. Int Endod J. 1995;28:12-8.

20- Saito S, Tosaki S, Hirota K. Characteristics of glass ionomer cement. In: Davidson CL, Mjör IA, eds. Advances in glass-ionomer cements. Berlin: Quintessence Publishing; 1999. p.15-50.

21- Sheth JJ, Jensen ME, Sheth PJ, Versteeg J. Effect of etching glass-ionomer cements on bond strength to composite resin. J Dent Res. 1989;68:1082-7.

22- Slutzky-Goldberg I, Slutzky H, Gorfil C, Smidt A. Restoration of endodontically treated teeth review and treatment recommendations. Int J Dent. 2009;2009:150251.

23- Sneed WD, Looper SW. Shear strength of a composite resin to an etched glass ionomer. Dent Mater. 1985;1:127-8.

24- Stockton LW, Tsang ST. Microleakage of Class II posterior composite restorations with gingival margins placed entirely within dentin. J Can Dent Assoc. 2007;73:255.

25- Taggart SE, Pearson GJ. The effect of etching on glass polyalkenoate cement. J Oral Rehabil. 1991;18:31-42.

26- Taher NM, Ateyah NZ. Shear bond strength of resin modified glass ionomer cement bonded to different tooth-colored restorative materials. J Contemp Dent Pract. 2007;8:25-34.

27- Tay FR, Pang KM, Gwinnett AJ, Wei SH. A method for microleakage evaluation along the dentin/restorative interface. Am J Dent. 1995;8:105-8.

28- Torii Y, Itota T, Okamoto M, Nakabo S, Nagamhe M, Inoue K. Inhibition of artificial secondary caries in root by fluoride-releasing materials. Oper Dent. 2001;26:36-43.

29- Tyas MJ. Clinical evaluation of glass-ionomer cement restorations. J Appl Oral Sci. 2006;14:10-3.

30- Zanata RL, Navarro MFL, Ishikiriama A, Silva e Souza Junior $\mathrm{MH}$, Delazari RC. Bond strength between composite resin and etched and non-etched glass ionomer. Braz Dent J. 1997;8:73-8. 